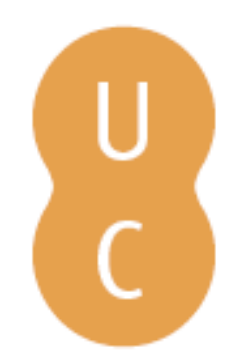

\title{
nommalina
}

\section{Os Lusíadas Y la épica española de los siglos XVI Y XVII}
Autor(es):
Extremera Tapia, Nicolás
Publicado por: Imprensa da Universidade de Coimbra
URL persistente:
URI:http://hdl.handle.net/10316.2/30822
DOI:
DOI:http://dx.doi.org/10.14195/978-989-26-0569-2_27
Accessed : $\quad$ 26-Apr-2023 12:16:04

A navegação consulta e descarregamento dos títulos inseridos nas Bibliotecas Digitais UC Digitalis, UC Pombalina e UC Impactum, pressupõem a aceitação plena e sem reservas dos Termos e Condições de Uso destas Bibliotecas Digitais, disponíveis em https://digitalis.uc.pt/pt-pt/termos.

Conforme exposto nos referidos Termos e Condições de Uso, o descarregamento de títulos de acesso restrito requer uma licença válida de autorização devendo o utilizador aceder ao(s) documento(s) a partir de um endereço de IP da instituição detentora da supramencionada licença.

Ao utilizador é apenas permitido o descarregamento para uso pessoal, pelo que o emprego do(s) título(s) descarregado(s) para outro fim, designadamente comercial, carece de autorização do respetivo autor ou editor da obra.

Na medida em que todas as obras da UC Digitalis se encontram protegidas pelo Código do Direito de Autor e Direitos Conexos e demais legislação aplicável, toda a cópia, parcial ou total, deste documento, nos casos em que é legalmente admitida, deverá conter ou fazer-se acompanhar por este aviso.

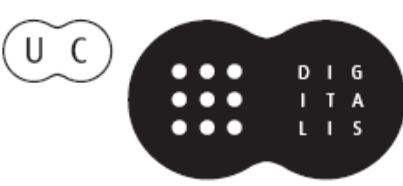




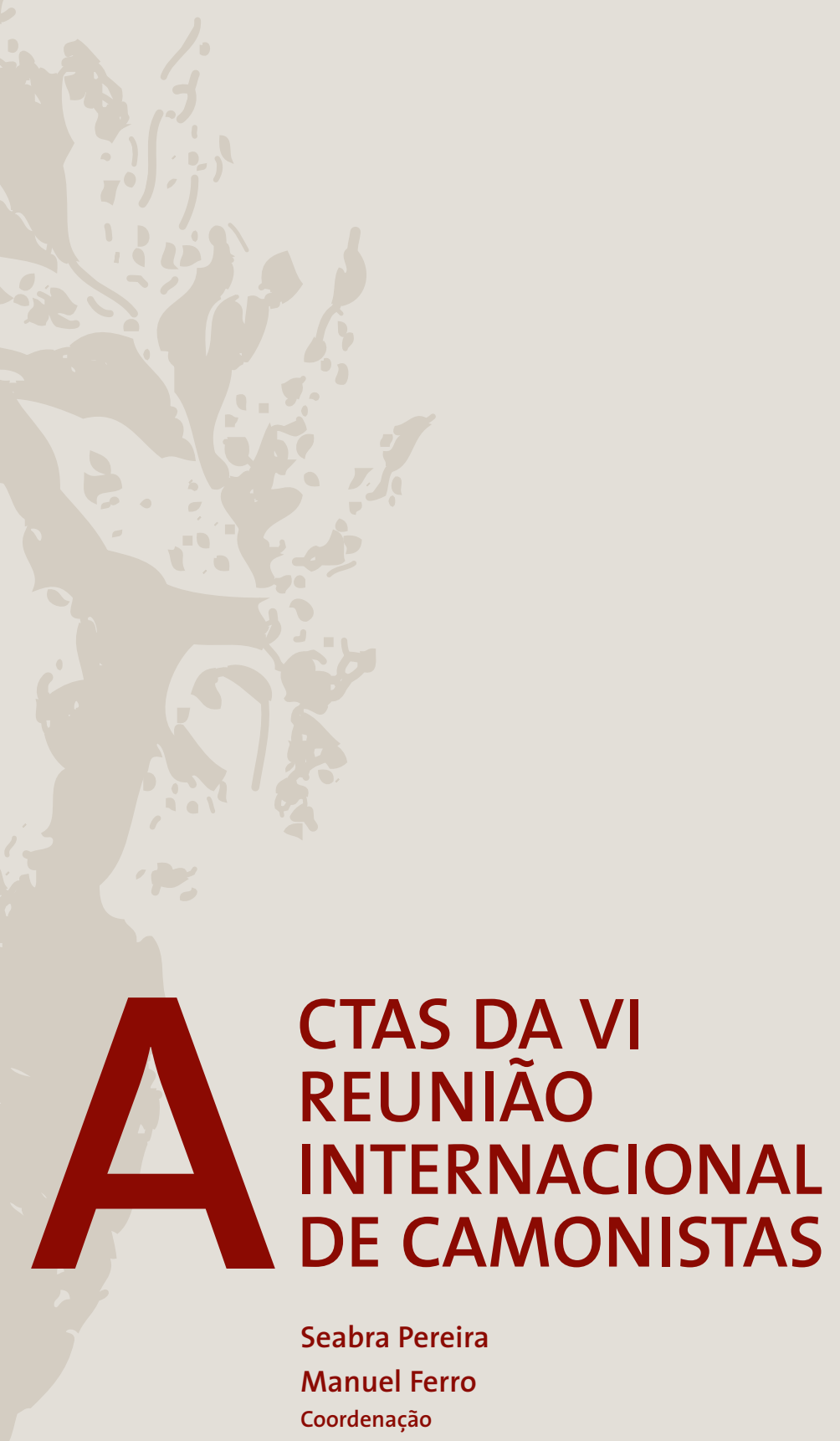




\section{Nicolás Extremera Tapia \\ Universidad de Granada}

\section{OS LUSÍADAS Y LA ÉPICA ESPAÑOLA DE LOS SIGLOS XVI Y XVII}

Es imposible recopilar las resonancias de Os Lusiadas en la poesía española del siglo XVI. Los poetas descubrieron el filón camoniano ante que los preceptistas y cada cual supo aprovechar lo que mejor convenía a su empeño.

La Felicísima Victoria de Corte-Real, publicada en 1578, pero acabada ya en 1574, es decir dos años después de la publicación del poema, respira ya la atmósfera de $O s$ Lusiadas e inicia su imitación en nuestras letras: después su fecunda influencia se extiende junto a la de Ercilla y Tasso a lo largo de la épica espańola del siglo XVI de tema histórico, fantástico, de descubrimiento o de cruzada, desde La Araucana (2a Parte, 1589) hasta la Mexicana (1588-94) de Lasso de la Vega, pasando por La Maltea (1582) de Hipólito Sanz y Las lágrimas de Angélica (1586) de Barahona de Soto ${ }^{1}$.

Algo semejante podríamos decir respecto al primer tercio del siglo siguiente. Raro es el poema épico de cualquier contenido: histórico, religioso, fabuloso, etc. que escapa al clima que el genial lusitano supo imponer en el panorama épico peninsular. La Conquista de la Bética de Juan de la Cueva (1603), la Genealogía toledana de Eugenio Martínez (1604), la Benedictina de fray Nicolás Bravo (1604), la Murgetana del Oriolano de Gaspar García Oriolano (1608), la Jerusalén Conquistada de Lope (1611), la Liga deshecha de João Mendes de Vasconcelos (1612), la Historia de Tobias de Caudibilla y Perpiñán (1615), el Sagrario de Toledo de José de Valdivielso (1616), el Certamen poético...de San Ramón Nonat de Francisco Gregorio Fanlo (1618), la Laurentina de Gabriel de Ayrolo Calar (1624), el David de Jacobo Uziel (1624), la Gigantomachia de Manoel de Galhegos (1626) y la de de Francisco de Sandoval (1630), el Fernando

\footnotetext{
${ }^{1}$ Sobre la influencia de Os Lusíadas en La Felicísima Victoria escribe Asensio unos interesantes párrafos en La fortuna de “Os Lusiadas” en Espańa (1572-1672) F.U.E., Madrid, 1973; en "Los Lusíadas" y las "Rimas» de Camões en la poesía española (1580-1640), Fundação Calouste Gulbenkian, Paris, 1982, estudia la influencia en la Segunda parte de la Araucana; véase también Lasso de la Vega, G., Mexicana, estudio y edición de José Amor Vázquez, Madrid, BAE, 1970. Por nuestra parte hemos encontrado en La Maltea una imitación del episodio de Inés de Castro en el C. IX estrs. 12 a 16, y otra en C. II estrs. 84-85, donde el símil del toro parece sacado de Lusiadas, I.88... Véase además el trabajo de Lara Garrido, J., "Geografía exótica y modelación narrativa: Camoens frente a Ariosto en Las Lágrimas de Angélica de Barahona de Soto”, en An Mal, I, pp. 293-312. Véase también Eugenio Fernández Almuzara, Relaciones de la épica de Lope de Vega y la de Camóes, Coimbra, Biblioteca da Universidade, 1936.
} 
o Sevilla Restaurada de Juan Antonio de Vera y Figueroa (1632) son obras que, aunque no mencionen a Camoens ni a Os Lusiadas, acusan claramente su influencia pese a su diversidad de asunto.

Categoría aparte merecen aquellos poemas, épicos o no, en que Os Lusíadas y Camoens aparecen mencionados como modelo de obra y poeta épicos ya sea:

\section{a) en el propio texto del poema.}

Como tal figura citada ya en 1602 en el Templo Militante de Bartolomé Cayrasco de Figueroa:

"No cante el Griego cálamo

De las armas Argólicas,

Ni el latino Bucólicas,

No entone Eneydas Mátua, Smirna Illiadas,

Ni muestre Lusitania sus Lusiadas,

En tanto que resuena el Canto insólito

De las santas Chilliadas,

Impresso en Iaspe, y luzido Chrisólito"

y en un poema de Luis de Belmonte Bermúdez que quedó manuscrito titulado La Hispálica cuyo elogio:

"Dichoso aquel varón Vasco de Gama,

Que dando las banderas al Oriente

Hurtó del Macedonio la gloria y fama

Sin que llore, como él, pluma excelente;

A aquella infusa luz, divina llama,

Que en su poeta se conoce ardiente,

Debe el honor que goza en sus Lusiadas,

Mayor que Troya a Eneidas, Grecia a Illiadas."2

recuerda mucho el de Cayrasco.

Así ocurre también en La iffanta coronada por el rey don Pedro, doña Inés de Castro, de Juan Soares de Alarcón, impresa en Lisboa en 1606, que nos muestra la historia a través de retratos de cosas notables y antiguos inventores de las artes, etc..., por el sabio Lycaonio que ocupa aquí el lugar de la Providencia, o el recurso tan debatido por la crítica contemporánea de mostrar el futuro por medio de un sueńo, en este caso guiado por un ángel que le hace conocer a Don Pedro el descubrimiento del camino hacia la India y la pérdida de Don Sebastián. Naturalmente el primer elogio a los de su nación, de los cuales cita a varios, se lo dedica Soares de Alarcón a Camoens (IV.42):

\footnotetext{
${ }^{2}$ Citado por Sousa Viterbo en «Camóes em Hespanha», Redacção do Círculo Camoniano, Porto, (1890), (pp. 12-13).
} 
"De nación Lusitana Camóes raro,

Corte real insigne, y tan famoso,"

y también en la obra del granadino Don Francisco Mosquera de Barnuevo, quien en su Numantina, publicada en 1612, rinde a Os Lusiadas el mejor tributo de la década, pues además de las frecuentes menciones a Camoens:

"Pues en materia de Poetas, es imposible referirlos, porque ya Garcilaso, Boscán, Camoes, Monte Mayor, Herrera, Don Jorge Manrique, el Marqués de Santillana, y otros infinitos quedan muy atrás con nuestro Lope de Vega..."

(C.II, p. 53)

y a su poema:

"Entre los descubridores del Oriente, se da el primer lugar a un Cauallero Portugés, llamado Don Basco de Gama, porque fue el primero de los del mundo que passó el Cabo de buena Esperança, y fue a la India Oriental, de donde nos viene la Especiería, drogas, y innumerable género de riquezas, el qual descubrimiento se hizo el año de mil y quinientos, en tiempo de el Rey Don Manuel de Portugal, dél canta Camoes en sus otavas admirables cosas, y en el Canto I: estancia 12

Douvos tambem aquelle illustre Gama

Que pera si de Eneas toma fama

y esta deve ser la razon porque le atribuyen a él el descubrimiento del cabo de buena Esperança, pero Iuan de Barros en el lugar que tengo referido, dize que lo descubrieron Bartolomé Díaz, Escudero de la Casa Real del Rey Don Juan el segundo, y Iuan Infante, que después fue conquistador de México. (...) De todos estos Héroes haze elegante relación Luys de Camoes en sus Lusiadas, y su comentador el Licenciado Manuel Correa, y el dicho Chronista Fray Juan de la Puente, que no olvidó nada” (p.75).

Refiriéndose a Viriato dice que toca su memoria entre otros: "Camoes canto $I$. estancia 36 y canto $3^{\circ}$ estancia 22 y su comentador Manuel Correa» y más adelante: «y pudiéramos celebrar las grandes victorias y virtudes de Trajano; nuestro sevillano, y de otros infinitos, de quien nos haze relación Camoes en su Lusiadas, y Manuel Correa su conmentador» (Canto III, p. 61v. y 62r.).

También imita Os Lusiadas en varias ocasiones a lo largo de su Numantina (resulta especialmente significativa la aparición en el C. III de la "Antigüedad" que según el modelo de Mena y Camoens descubre al autor el sitio donde estuvo Numancia y otros hechos e historias de la ciudad).

Quizá el elogio más célebre sea el que figura en la p. 25 v. del Laurel del Apolo, publicado por Lope de Vega en 1630 (con Aprobación de 1629), dice así:

"Y al divino Camoes

En Indianos Aloes

Que riega el Ganges, y produze Hidaspes,

Durmiendo en bronze, porfidos, y jaspes 
(Fortuna estraña que al ingenio aplico

La vida pobre, y el sepulcro rico)

Porque si despertaran,

Y a las Cortes Parnasides llevaran;

Docto Corte Real, tu nombre solo,

Aun no quedara con el suyo Apolo

Como lo muestran oy vuestras Lusiadas

Postrando Eneydas, y venciendo Iliadas.

Que triste suerte, que notables penas,

Acabada la vida hallar Mecenas!

Mas no por eso puede

Dexar de ser gloriosa vuestra fama,

Si bien claro Luis la tuya excede

Por quanta luz derrama

El farol Didimeo,

Y mas quando te veo

Bañar pluma de Fenix tinta de oro,

Diziendo con decoro

Y magestad sonora,

Por la lealtad, que nunca el tiempo olvida,

Que mais anos servira se naon fora

Pera tan largo amor tan curta a vida."

b) en los prólogos:

Sabida es la importancia que adquieren los prólogos, muchas veces auténticos tratados de poética, durante el Siglo de Oro. El célebre del Brocense a la versión de Os Lusíadas de Luis Gómes de Tapia marca la inclusión del poema en este género en el que naturalmente sólo entran obras señeras de la épica universal. Durante el XVII asistiremos a un aumento paulatino de su presencia que quedará ya para siempre entre las obras selectas de la épica universal.

La Epistola a los lectores que precede a La restauración de España de Cristóbal de Mesa, poema en diez cantos, de tema histórico y materia en parte común con $O s$ Lusiadas, publicado en Madrid en 1607, pero con Censura y Privilegio dados en Valladolid en 1604, dice:

"[...] Si pareciere obra corta me desculpe Lucano, que teniendo tan amplia materia como las guerras civiles de que resultó a César el Imperio del mundo, no hizo más que diez libros, ni Luys de Camoes mas que diez Cantos en sus Lusiadas, aunque el uno es más Historiador que Poeta, y el otro más Lírico que Heroyco, según la amenidad de concetos, y la diversidad de flores que esparce por todos sus versos, cosa agena, es la gravedad y grãdeza Épica [...]”.

En este misma idea de asociar a Camoens con Lucano como prototipos del poema épico histórico insiste Lope en el Prólogo a su Jerusalén Conquistada, publicada en Barcelona en 1609, y que tanta difusión alcanzó a lo largo del siglo: 
“Con esto pienso q he respondido a alguna objeció tácita de los q mirã la Poesía como historia de q tã culpado ha sido el famoso Lucano, quáto celebrado en nuestros tiepos el Portugués Camoes".

En el año de 1621, unos Aphorismos y Exemplos políticos, y militares, sacados de la primera Década de Juan de Barros, publicados en Lisboa por Don Fernando Alvia de Castro, nos ofrecen en un prólogo del autor, junto al elogio del poeta, unas referencias a su biografía que aportan alguna información nueva:

“(...) lastimándome también en no se aver honrado, y gratificado grandemente los dos admirables sujetos desta era naturales suyos Barros de quien voy hablando el uno, y Luis de Camoes el otro: tales, que por la profession que siguieró de la historia, y Poesia, no solo deuen compararse a los mejores antiguos, y modernos de todas las naciones, pero aventajarlos a los mas celebrados por ello, cuyos nombres, y obras oy se reverencian, y estiman mucho, dignos por cierto estos dos insignes Españoles, de grandes premios, y honras, y de mejor fortuna que tuvieron. Faltoles quiça por merecerlo, que la desgracia suele perseguir a los mas buenos, ó por mal clima, ó cortedad del tiempo que alcançaron, los effectos califican bien esta verdad, el primero ya que tuuo algo, fue poco, y differente de su talento, y trabajo. Camoes vivió con mucha pobreza, la fortuna parece que por particular trofeo, y gloria suya, le truxo siempre debaxo de los pies, loçana de atropellar, y tener rendido un ingenio tan suave, agudo, y gallardo, echando en ello tanto resto, que tras la vida inquieta, menesterosa, y atropellada que passó: con varias peregrinaciones, quando por mar, quâdo por tierra; hallando en Asia la misma infelicidad que dexava en Europa, mas los Cielos, que el animo (a que ańado yo, y desgracias) dixo Horacio mudan los que navegan; murió miserablemete en un hospital desta Ciudad ${ }^{3}$."

Dos años más tarde, en 1623, otra vez Lope, en un Elogio suyo a Soto de Rojas que figura a manera de prólogo en el Desengaño de amor en rimas, dice refiriéndose a Soto de Rojas:

"Llamábase en nuestra Academia, el Ardiente, nombre que tomó para sí el excelente portugués Luis de Camoens, cuando dijo:

E uas[sic] Tagides minhas, pois criado

tendes en mi hum novo engenho Ardente.

$\mathrm{Y}$ vino bien esté título a su ingenio, que en la lengua latina ardiente, es ingenioso (...).”

En el segundo tercio del siglo Os Lusíadas continúan su trayectoria de modelo épico junto a los más afamados de los antiguos y modernos. Miguel de Silveira, quien publicó en Nápoles en 1638 un poema heroico titulado El Macabeo, dedicado a «la Restauración del Templo de Jerusalen, hecha por el invicto capitán...» dice en el Prólogo:

\footnotetext{
${ }^{3}$ El subrayado es nuestro.
} 
«(...) Tuvieró los Griegos a Homero, honor de su patria por cuya naturaleza litigaró tâtas Ciudades. Los Latinos despues a Virgilio, que solo có su imitació ha conseguido inmortal renombre; favorecio a los modernos nuestra edad, con el Tasso, gloria de Italia, y emulacion de los antiguos; y con Camoins[sic] lustre de Lusitania, que excedio a muchos en el espiritu (...)».

En la misma línea de elogio se sitúan:

Antonio Henríquez Gómez en el Prólogo de su Sansón Nazareno, publicado en Ruan en 1656:

“(...) Es tan dificil acceder ó llegar á la cumbre de un Poema heroïco, que entre tantos como los an escrito, solos cinco gozaron el laurel. El oprimero fue Homero con su Ulisea en Griego, el segundo Virgilio con la Eneyda en Latin, el tercero el Taso con su Ierusalen Toscana; el Camóes el quarto con su Liusiada[sic] en Portugues, y el Doctor Silveyra el quinto con el Machabeo en Castellano. Estos Varones illustraron estos cinco Idiomas sin que tubiese ninguno en el suyo quien le pudiese igualar. Homero fue divino, Virgilio eminente, Camóes admirable, el Taso profundo, y Sylveyra heroïco, (...) Camóes en el espíritu excedió a los antiguos quanto más a los modernos (...)."

Y fray Diego Sáenz Ovecuri en la Isagoge a los Lectores que precede a su Thomasiada, publicada en Guatemala en 1667, que inaugura el último tercio del siglo:

"Intitulo pues esta obra, la Thomasiada, imitando á Homero, que del Ilion intitulô las suyas Iliadas, á Virgilio, que llamô á las de Eneas, Eneidas, á Camôes, que de Luis, llamó las suyas Lusiadas, al que escriviô las hazañas de Carlos Quinto, que las denominô Carolêas, al que escriviô las Guerras de Numancia, que las intitulô Numantinas; y últimamente á D. Francisco de Trillo, y Figueroa en su Poema heroico, del Gran Capitan en Nápoles, que lo nombrô Napolisea, porque siempre me preciê de imitar á los otros, y en especial, a los antiguos», y más adelante: "Imito á los mejores Poetas, o à lo menos lo procuro, de los Latinos, à Virgilio, Ovidio, y el Tarraconense Marcial, de los Castellanos, al antiguo Iuan de Mena, à Garcilaso, al celebre Lope, en su Ierusalem Conquistada, y su Centuria de Sonetos, à todo Don Luis de Gongora, muchas vezes al Conde de Villamediana, à Don Francisco de Quevedo en su Parnaso, à Fernando de Herrera, à Don Garcia de Salcedo, al insigne Montalvan, à Don Agustin del Hierro, al Maestro Silveira, al Portugues Camôes, à mi señor el Conde de Salinas, dulcissimo sin disputa Cisne, como lo colegirâs deste Soneto, que por de mi señor te lo estampo.

Soneto

Si por Raquel gentil Serrana bella,

Siete ańos de Pastor Iacob servia,

Si le engañaron con su hermana Lia,

Otros siete bolviô à servir por ella.

(...)

No parece, que se pudo mejorar, y porque discutras quien imitó à quien, escucha este otro de Camôes», y copia Sete annos de Pastor Iacob servia, y más adelante: "Lo que procuro es discantar sus mas selectos hechos, no como se debe, sì como puedo; pues solo êl se puede dignamente cantar con mas razon, (si bien no tuvo aquel poca) que Diego Bernardes assentô en un Soneto à Camôes. 
Quem lovara Camoens,

Que elle naon seja?

Quê naon veé que cása en vaon, engenho e arte?

Elle se louva assi soo, em toda parte,

E toda parte, elle soo henche de inveja."

\section{c) en los preliminares}

Entre los preliminares de la Liga deshecha... de Iuane Mendez de Vasconcelos, publicada en Madrid en 1612, pero con licencias en 1611, figura un poema de Gerónimo Gómez de Montalvo, la tercera de cuyas estrofas dice así:
"Son vuestros acentos tales,
Que hazen la fama inmortal,
Y si los hizo inmortales,
Un Camoes en Portugal,
Vos en muchos Portugales"

por lo demás la Liga..., como casi todos los poemas citados hasta ahora, rinde su tributo a Os Lusíadas generalmente imitando la Dedicatoria para dejar así constancia de su querida filiación camoniana.

Más expresivo resulta el último terceto de un soneto "De un amigo al Autor" que figura entre los preliminares de El Triumpho más famoso que hizo Lisboa a la entrada del Rey Don Phelippe Tercero..., compuesto por Gregorio de San Martín y publicado en Lisboa en 1624 (aunque con licencias de 1623). El terceto dice así:

"Mas suavidad de exemplos no se hallara

Nuevo Camóes que muestra en este dia

Sobrenatural los rios deteniendo."

Otro poema, también muy influenciado por Os Lusíadas, el Poema heroyco del assalto y conquista de Antequera, compuesto por Don Rodrigo de Carvajal y Robles y publicado en 1627, trae entre sus preliminares un parecer del licenciado Antonio Maldonado y Silva en el que afirma que «tiempo, ni mordaz (que ambos consumen quanto es morte) an podido poner en olvido en tantos siglos a Homero, Virgilio, Garcilaso, Camoes, Dante, Taso, peregrinos en el mundo, no solo porque anden solos, pero sin peligro, por singulares en dotrina y deleite?»

Mayor consideración aún alcanza Camoens en un poema de "El Conde Claros, al licenciado Tomé de Burguillos" que precede las Rimas humanas y divinas del licenciado Tomé de Burguillos, publicadas en Madrid en 1634, dice así:

"España de Poetas que te honoran

Garcilaso es el Principe, el segundo

Camoes, tan heroico, tan fecundo,

Que en repetido Sol su nombre adoran.”

De igual tenor, para confirmar la fama de Camoens mediado el siglo, el juicio que contine la "Censura del Reverendíssimo Padre Agustín de Castro..." que precede la 
Nápoles recuperada de Don Francisco de Borja, Príncipe de Esquilache, publicada en Zaragoza en 1651: «(...) Glorianse los Griegos de su Homero; los Latinos de la Eneida de Virgilio; los Italianos del Tasso; los Portugueses de Camoens (...)». 